Article

\title{
Effects of Steel Slag Powder and Expansive Agent on the Properties of Ultra-High Performance Concrete (UHPC): Based on a Case Study
}

\author{
Shunkai Li ${ }^{1,2, *}$, Shukai Cheng ${ }^{2}$, Liwu Mo ${ }^{1,3}$ and Min Deng ${ }^{1,3}$ \\ 1 College of Materials Science and Engineering, Nanjing Tech University, Nanjing 21009, China; \\ andymoliwu@njtech.edu.cn (L.M.); dengmin@njtech.edu.cn (M.D.) \\ 2 CCCC Wuhan Harbor Engineering Design \& Research Institute Co., Ltd., Wuhan 430000, China; \\ chengsk@whut.edu.cn \\ 3 State Key Laboratory of Materials-Oriented Chemical Engineering, Nanjing 210009, China \\ * Correspondence: lishunkai7910@163.com; Tel.: +86-189-7157-3782
}

Received: 7 January 2020; Accepted: 1 February 2020; Published: 3 February 2020

\begin{abstract}
In view of the performance requirements of mass ultra-high performance concrete (UHPC) for the Pang Gong bridge steel cable tower in China, the UHPC incorporating of steel slag powder and hybrid expansive agents is optimized and prepared. The effects of steel slag powder and hybrid expansive agents on the hydration characteristics and persistent shrinkage of UHPC are investigated. The results indicate that $15 \mathrm{wt} . \%$ steel slag powder and $5 \mathrm{wt} . \%$ hybrid expansive agents can effectively reduce the drying shrinkage deformation of UHPC with a slight decrease of strength. Heat flow calorimetry results show that the incorporation of steel slag powder and expansive agents decreases the hydration heat at three days. Moreover, the obtained adiabatic temperature rise of UHPC is $59.5^{\circ} \mathrm{C}$ and the total shrinkage value at 180 days is $286 \mu \varepsilon$. The hydration heat release changes of large volume UHPC in the steel-concrete section of cable tower is agreed with the result of adiabatic temperature rise in the laboratory.
\end{abstract}

Keywords: ultra-high performance concrete (UHPC); steel slag powder; expansive agent; compact stacking theory; total shrinkage; hydration process

\section{Introduction}

Ultra-high performance concrete (UHPC), as a new cement-based material, is different from traditional high strength concrete (HSC) and steel fiber reinforced concrete (SFRC), which has excellent mechanical and durability properties [1-4]. Normally, the compressive strength of UHPC is higher than $150 \mathrm{MPa}$ for structural concrete [5-7] and shows outstanding performance [8-10]. UHPC is produced via optimizing the granular mixtures at very low water-to-binder ratio $(w / b<0.2)$, using high amount of binding materials and a certain amount of steel fibers [11-14]. Moreover, UHPC could satisfy the requirements of structural engineering with its own high strength, toughness and durability. Now it has evolved as a commercial concrete.

Owing to its outstanding mechanical properties and durability, UHPC has been widely used in thin concrete structure in China such as steel bridge deck pavement, wet joint, small prefabricated components, etc. [15]. However, due to the extremely low water-to-binder ratio of around 0.2 and the typically high binder content of $800-1200 \mathrm{~kg} / \mathrm{m}^{3}$ in UHPC, the shrinkage of UHPC (usually the total shrinkage $>500 \mu \varepsilon$ ) is greater than that of the conventional high performance concrete (HPC) [16-18]. Generally, the autogenous shrinkage of UHPC accounts for a larger proportion of total shrinkage, while the dry shrinkage is smaller. Such a great shrinkage developed at the early ages (autogenous shrinkage) can induce potential cracking of UHPC, and thus further reduce its mechanical properties 
and durability $[19,20]$. Therefore, the shrinkage problem of UHPC is one of the important factors restricting its engineering application, and has become a hot and difficult point in current research. Particularly, when the UHPC is used in mass concrete structures, the large shrinkage deformation accompanied with huge cement hydration heat liberation is usually caused, which seriously restricts the stability, reliability and sustainability of concrete structure.

To reduce the magnitude of shrinkage and cracking potential, several mitigation strategies have been developed to reduce the shrinkage of UHPC. For instance, cement was replaced at different levels by industrial by-products such as ground-granulated blast-furnace slag (GGBS) [21], fly ash (FA) [6,22-24], and rice-husk ash (RHA) [25]. The use of these industrial by-products in UHPC could not only increase the long-term strength, decrease hydration heat and the shrinkage, but also reduce the cost and environmental burden [26,27]. Nevertheless, the by-products such as FA and RHA are lack in some regions. Therefore, there is an increasing need to seek an effective substitute for cement in the wide range applications of UHPC. Recently, limestone powder (LP), a kind of supplementary cementitious materials, has been more and more used in the cement-based materials production due to its stable supply, ease of quality control and reasonable price, which contributes to reduction of cement content. Previous literatures reported that the LP not only played at physical role of filling effects but also participated in hydration reaction [28-30]. In addition, it is also found that the use of steel slag powder as a mineral admixture in concrete could improve the workability, retard the hydration and decrease the autogenous shrinkage of concrete at early ages [31]. While the addition of steel slag powder tends to have a negative effect on the mechanical properties and durability. Hence, there is a clear motivation to effectively optimize the content of steel slag powder and expansive admixture to obtain a suitable strength but lower shrinkage and hydration heat in UHPC.

Many researchers have already done some interesting investigations to reduce the shrinkage of UHPC with the addition of high-performance admixtures. It has been reported that the incorporation of calcium-sulfoaluminates-CaO based expansive agent (CSA-CaO EA) could effectively reduce autogenous shrinkage of UHPC by over $20 \%$ and show a better contribution to shrinkage compensation [32]. A study indicated that the addition of $7.5 \%$ EA and $1 \%$ shrinkage-reducing agent reduced the shrinkage by approximately $80 \%$ after 1 day [33]. At present, the ettringite based EA has been utilized to reduce the autogenous shrinkage and drying shrinkage of UHPC, but the addition of EA may reduce the workability of fresh concrete, increase the air content and decrease the strengths [34]. Therefore, both the mechanical and durability properties of UHPC containing EA should be carefully investigated.

This study is carried out to investigate the influence of steel slag powder (SSP) and expansive agents (EA) on the performance of UPHC, and then evaluate the feasibility of using the two minerals in UHPC in the main tower of Pang Gong Bridge (Xiangyang, China). The UHPC is designed to be used as the connecting material between the steel and concrete structures with a volume of $300 \mathrm{~m}^{3}$. Cement is replaced with LP at a substitution level of $15 \mathrm{wt} . \%$. SSP and EA are added as replacements of cement by different proportions, respectively. The workability, mechanical properties, drying shrinkage, hydration heat, and adiabatic temperature rise of UHPC is investigated. Additionally, the on-site temperature monitoring of UHPC with added SSP and EA is also assessed.

\section{Materials and Methods}

\subsection{Materials}

In this study, UHPC is designed to gain a compressive strength higher than $120 \mathrm{MPa}$ and a high flowability by adopting steel slag power and limestone powder. The cementitious materials used in this study were Class 42.5 Ordinary Portland cement (OPC, Huaxin Cement Co., Ltd., Huangshi, China), silica fume (SF, Southeast Star Technology Development Co., Ltd., Chengdu, China), unidentified superfine limestone powder (LP) and steel slag power (SSP, Wuhan Iron Group, Wuhan, China). The physical properties and chemical compositions of the cementitious materials are shown in Table 1. 
Continuously graded quartz sand (QS, $0.6-1.25 \mathrm{~mm})$ and quartz powder $(\mathrm{QP}, 0-0.6 \mathrm{~mm})$ are used as fine aggregates. A highly effective polycarboxylate superplasticizer (SP) (Wuhan Harbor Engineering Design \& Research Institute Co. Ltd., Wuhan, China) with a solid content of $32 \%$ and a water reduction rate of $30 \%$ is also used in this paper. In order to reduce the shrinkage of UHPC, a hybrid magnesia expansive agent (EA, Wuhan Sanyuan Special Building Materials Co. Ltd., Wuhan, China) is used in this study. The hybrid magnesia expansive agent is a mixture of calcium oxide $(\mathrm{CaO})$ and magnesium oxide $(\mathrm{MgO})$ and the weight ratios of $\mathrm{CaO}$ and $\mathrm{MgO}$ based $\mathrm{EA}$ are $56.5 \%$ and $22.6 \%$, respectively. Moreover, straight steel fibres (SSF) with $13 \mathrm{~mm}$ length and $0.22 \mathrm{~mm}$ diameter are utilized in the UHPC.

Table 1. Chemical compositions of the cementitious materials (\%).

\begin{tabular}{ccccc}
\hline Chemical Composition & OPC & SF & LS & SSP \\
\hline $\mathrm{Al}_{2} \mathrm{O}_{3}$ & 5.69 & 0.25 & 0.09 & 0.84 \\
$\mathrm{SiO}_{2}$ & 21.27 & 94.65 & 0.41 & 12.67 \\
$\mathrm{CaO}$ & 60.15 & 0.36 & 54.75 & 48.66 \\
$\mathrm{MgO}$ & 2.41 & 0.47 & 2.61 & 2.80 \\
$\mathrm{Fe}_{2} \mathrm{O}_{3}$ & 3.16 & 0.15 & 0.11 & 21.70 \\
$\mathrm{Na}_{2} \mathrm{O}$ & 0.14 & 0.13 & - & - \\
$\mathrm{K}_{2} \mathrm{O}$ & 0.69 & 0.84 & - & - \\
$\mathrm{SO}_{3}$ & 3.66 & 0.69 & - & - \\
$\mathrm{L.O.I}$ & 3.95 & 2.29 & 39.9 & 8.59 \\
Physical properties & - & - & - & - \\
Specific gravity $\left(\mathrm{kg} / \mathrm{m}^{3}\right)$ & 3210 & 2300 & 2640 & 2810 \\
Specific surface area $\left(\mathrm{m}^{2} / \mathrm{kg}\right)$ & 380 & 3800 & 1200 & 600 \\
Water demand ratio $(\%)$ & 100 & 115 & 105 & 95 \\
\hline
\end{tabular}

\subsection{Experimental}

\subsubsection{Mix Design of Concrete Skeleton}

The UHPC mixtures are designed by using the modified Andreasen and Andersen model (A\&A) model in according to the most closely packed principle [5,35]. The distribution coefficient (q) may be used to determine the proportions of fine and coarse particles in the mixture, of which the value is selected as 0.23 based on the available literature [36,37]. The UHPC mixtures are listed in Table 2. It can be found that the amount of SSP in the designed UHPC are $10 \mathrm{wt} . \%, 15 \mathrm{wt} . \%$ and $20 \mathrm{wt} . \%$, respectively. Two addition dosage of EA, namely $5 \mathrm{wt} . \%$ and $8 \mathrm{wt} . \%$, are added in the mixture.

Table 2. Mix proportion of the designed UHPC.

\begin{tabular}{|c|c|c|c|c|c|c|c|c|c|c|}
\hline No. & $\begin{array}{c}\text { OPC } \\
\left(\mathrm{kg} / \mathrm{m}^{3}\right)\end{array}$ & $\begin{array}{c}S F \\
\left(\mathrm{~kg} / \mathrm{m}^{3}\right)\end{array}$ & $\begin{array}{c}\mathrm{LP} \\
\left(\mathrm{kg} / \mathrm{m}^{3}\right)\end{array}$ & $\begin{array}{c}\text { SSP } \\
\left(\mathrm{kg} / \mathrm{m}^{3}\right)\end{array}$ & $\begin{array}{c}\text { EA } \\
\left(\mathrm{kg} / \mathrm{m}^{3}\right)\end{array}$ & $\begin{array}{c}\mathrm{QP} \\
\left(\mathrm{kg} / \mathrm{m}^{3}\right)\end{array}$ & $\begin{array}{c}\text { QS } \\
\left(\mathrm{kg} / \mathrm{m}^{3}\right)\end{array}$ & $\begin{array}{l}\text { Water } \\
\left(\mathrm{kg} / \mathrm{m}^{3}\right)\end{array}$ & $\begin{array}{c}\mathrm{SP} \\
\left(\mathrm{kg} / \mathrm{m}^{3}\right)\end{array}$ & $\begin{array}{c}\text { SSF } \\
(\text { vol.\%) }\end{array}$ \\
\hline R0 & 700 & 100 & 200 & 0 & 0 & 150 & 850 & 160 & 18 & 2 \\
\hline R1 & 600 & 100 & 200 & 100 & 0 & 150 & 850 & 160 & 18 & 2 \\
\hline R2 & 550 & 100 & 200 & 150 & 0 & 150 & 850 & 160 & 18 & 2 \\
\hline R3 & 500 & 100 & 200 & 200 & 0 & 150 & 850 & 160 & 18 & 2 \\
\hline $\mathrm{R} 4$ & 665 & 100 & 200 & 0 & 35 & 150 & 850 & 160 & 18 & 2 \\
\hline $\mathrm{R} 5$ & 515 & 100 & 200 & 150 & 35 & 150 & 850 & 160 & 18 & 2 \\
\hline R6 & 494 & 100 & 200 & 150 & 56 & 150 & 850 & 160 & 18 & 2 \\
\hline
\end{tabular}

The optimized grading curves of the designed mixtures are shown in Figure 1. Mix-1, Mixt-2 and Mix-3 denote the R1, R2 and R3, respectively. It can be observed that there is no difference between particle size distributions of the cementitious materials due to the fact that SSP and OPC have very similar particle size distributions. 


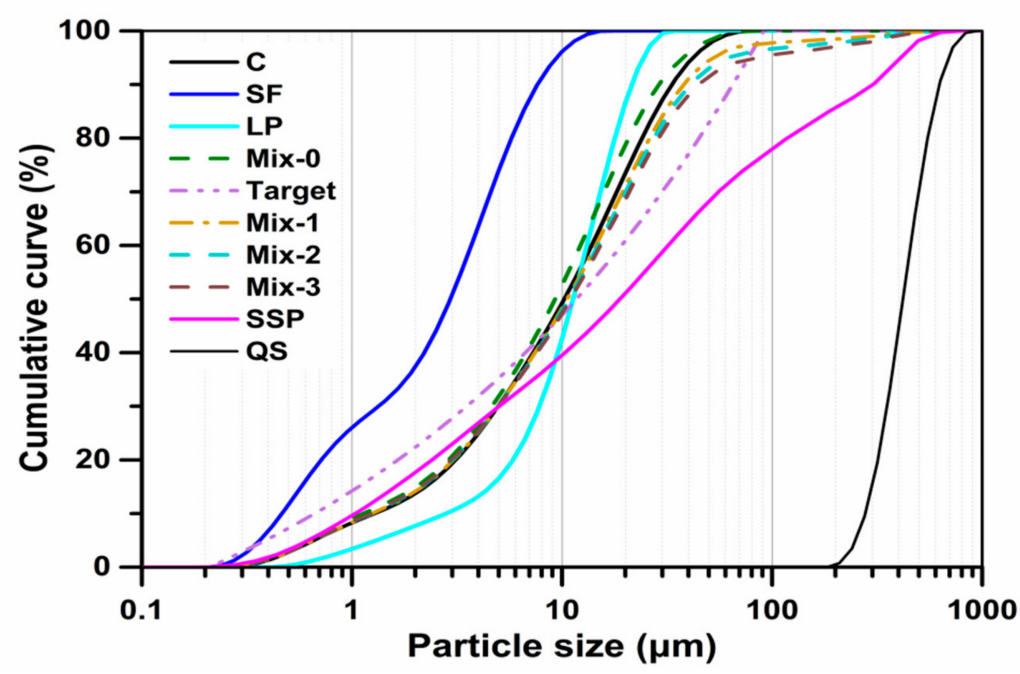

Figure 1. Particle size distributions (PSD) of the involved ingredients, the target and optimized grading curves of the UHPC mixtures.

\subsubsection{Flowability}

The workability of the designed fresh UHPC with steel fibers is evaluated using flow test in accordance with the EN 12350-8, which are normally used for evaluating self-compacting concrete. Two diameters (perpendicular to each other) of the fresh UHPC are recorded and their average value is taken as the flowability.

\subsubsection{Mechanical Properties}

The designed UHPC mixtures are cast in molds with the size of $100 \times 100 \times 100 \mathrm{~mm}$, which are demolded $24 \mathrm{~h}$ after casting and then cured in water at the temperature of $20 \pm 2{ }^{\circ} \mathrm{C}$. The compressive strength of the samples is tested according to the Chinese standards GB/T 50081-2002. Three specimens are tested for each mixture.

\subsubsection{Total Shrinkage}

According to the JTG E30-2005, the total shrinkage measurement of the designed UHPC mortar is conducted. Each group with three samples (size of $40 \mathrm{~mm} \times 40 \mathrm{~mm} \times 160 \mathrm{~mm}$ ) is cured in standard environment with the temperature of $20 \pm 2{ }^{\circ} \mathrm{C}$ and the relative humidity of $98 \pm 2 \%$ for 3 days. And then they are placed in the drying room with a condition of temperature of $20 \pm 2{ }^{\circ} \mathrm{C}$ and relative humidity of $60 \pm 5 \%$. The measurements of total shrinkage are conducted for 1 day, 7 days, 14 days, 28 days, 42 days, 56 days, 90 days, 120 days, 150 days and 180 days. The initial length of the specimens is $\mathrm{L}_{0}$ and the test length at the corresponding time is $\mathrm{Lx}$.

\subsubsection{Hydration Heat}

The prepared fresh paste is strictly designed according to the mix proportion and the rate of heat liberation and total heat within 3 days are recorded using an TAM AIR isothermal calorimetry. Then, the obtained results are normalized to the weight of the cement or binder.

\subsubsection{Adiabatic Temperature Rise}

The fresh UHPC paste is added and vibrated, and then fulfilled in the $50 \mathrm{~L}$ cylindrical tin bucket. The adiabatic temperature rise of UHPC is carried out by using thermo-physical parameter measuring (NELD-TV810 Instrument, Beijing, China) in accordance with the Chinese standards CSL 352-2006. 


\section{Results and Discussion}

\subsection{Slump Flow}

The slump flow of the designed UHPC incorporated with SSP and EA is shown in Figure 2. It is observed that the slump flows of UHPC mixtures with $0 \%, 10 \%, 15 \%$, and $20 \%$ SSP are $610,610,605$, and $600 \mathrm{~mm}$, respectively. This is attributed to the fact that, when the SSP is used as supplementary cementitious materials (SCMs) in UHPC, it decreases the stress state between particles, aggregate and mortar, and therefore results in slight reduction of the slump flow [35]. In addition, the specific surface area of SSP is higher than that of cement, resulting in water demand increase, which also reduce the slump flow. Moreover, it is clear that the incorporation of EA exhibits negative effects on the slump flow of UHPC. In contrast to R0, the addition of $5 \mathrm{wt}$.\% EA (R4) obviously declines the flow value of UHPC mixture. The reduction in flow slump may be related to the possible higher specific surface area of EA. While the combined addition of $15 \mathrm{wt} . \%$ SSP and $5 \mathrm{wt} . \% \mathrm{EA}$, similar trends are also observed in the test results. However, when the replacement level of EA is 8 wt.\% (R6), the slump flow is reduced significantly, which reaches a minimum slump of $560 \mathrm{~mm}$. Therefore, based on the obtained experimental results, it can be concluded that the incorporation of the EA at the dosages of $5 \mathrm{wt}$. $\%$ can achieve the optimal workability of UHPC.

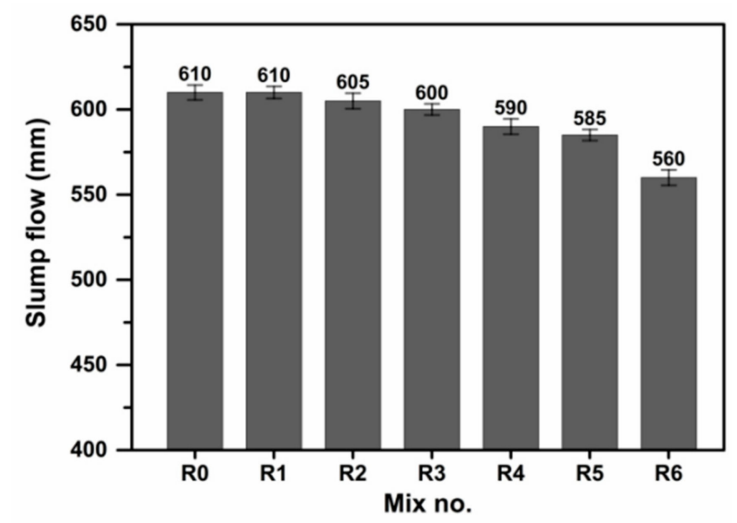

Figure 2. Slump flow of the designed UHPC.

\subsection{Compressive Strength}

The compressive strengths of the UHPC specimens at 1 day, 7 days, and 28 days are shown in Figure 3. It is evident that the compressive strength of UHPC gradually decreases with the increasing content of SSP. Compared to the sample R0, the strength decreasing ratios of samples at 1-day curing are $7.4 \%, 8.7 \%$, and $15.0 \%$, respectively. While the 28 days strengths of UHPC are decreased by $5.1 \%$, $6.4 \%$ and $13.1 \%$, respectively. When higher amount (20 wt. $\%$ ) of SSP is utilized, the 28-day strength drops to $132.6 \mathrm{MPa}$. This is attributed to the lower reactivity of SSP with an activity index of $82.6 \%$ at 28 days, and thus makes very limited contribution to strength development of UHPC. During the early ages of hydration, the hydration activity of SSP is substantially lower than that of OPC. Moreover, the SSP has a retarding effect on the hydration of cement due to its lower reactivity [27]. Thus, the early compressive strength of UHPC is slight lower than the control group. However, with the hydration process continuing, the reactivity of SSP can provide suitable strength development of UHPC. Hence, to guarantee the compressive strength of the designed UHPC, it is advised to incorporate less than $15 \mathrm{wt} . \%$ SSP. Additionally, the results also indicate that the added EA has negative effects on the compressive strength. It is evident that, for the evaluated dosages, the inclusion of EA clearly decreases the strength. Similarly, the combination of SSP and EA induces the decrease in strength. It is noticed that the compressive strengths of R3 and R5 samples containing $15 \mathrm{wt}$.\% SSP at 28 days are higher than $140 \mathrm{MPa}$, which remains acceptable. 


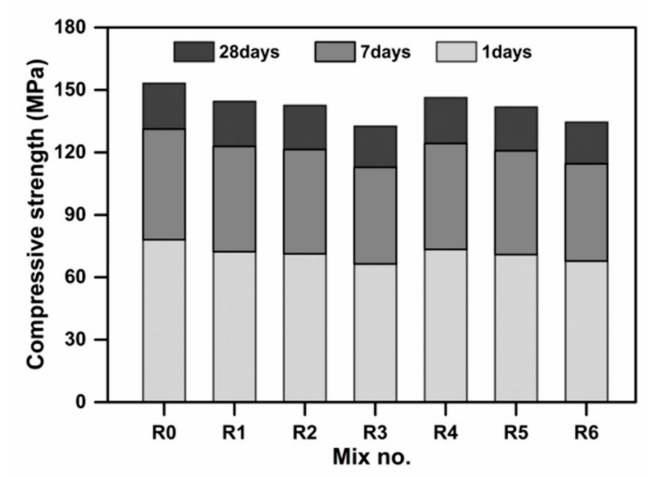

Figure 3. Compressive strengths of the designed UHPC at different curing ages.

\subsection{Total Shrinkage}

The total shrinkage of UHPC sample measured as a function of up to 180 days are presented in Figure 4. It can be seen that the shrinkage of UHPC in the first seven days is fast. The difference of total shrinkage of each sample is insignificant, and a clear distinction could be observed among all the UHPC mixtures at seven days. Afterwards, the increase rate gradually decreases, and the specimens continue to shrinkage within 14 days to 180 days. Due to the extremely low w/b in UHPC, the mixed water is quickly consumed at the early stage of hydration, inducing rapid decrease of relative humidity inside the system. In addition, outside moisture does not easily exchange with the inner moisture of UHPC due to the lower porosity and dense microstructure of UHPC [38,39]. As a result, the early shrinkage development of UHPC is comparatively rapid than the normal Portland cement concrete.

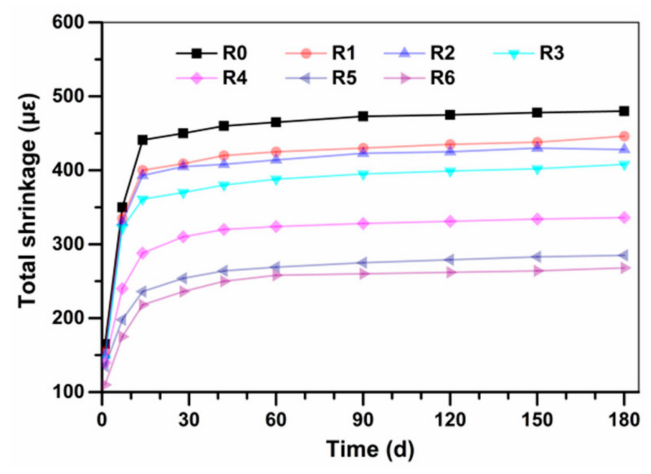

Figure 4. Total shrinkage development of the designed UHPC.

The shrinkage of all specimens is smaller than $500 \mu \varepsilon$ at the age of up to 180 days. The replacement of cement by SSP can not only reduce the cement content, but also restrain the shrinkage of UHPC. For instance, the drying shrinkage of UHPC added with $10 \%, 15 \%$ and $20 \%$ SSP at $180 \mathrm{~d}$ are $446 \mu \varepsilon, 428 \mu \varepsilon$ and $408 \mu \varepsilon$, respectively. Compared with UHPC without SSP, the total shrinkage of UHPC added with $10 \%, 15 \%$ and $20 \%$ SSP at 180 days are declined by $7.1 \%, 10.8 \%$ and $15.0 \%$, respectively. The reason can be attributed to multiple reasons such as the shortening of early-age period of the concrete and the cement dilution effect [31]. In addition, both the accelerated cement hydration and the refinement of pore structure owing to the changed particle packing of binder can contribute to this result. Eventually, the total shrinkage of UHPC incorporating of SSP is lower than the control group.

The addition of EA is very effective in reducing total shrinkage of UHPC. The total shrinkage of UHPC (R4) added with 5\% EA are approximately $40 \%$ lower than that without addition of EA. Replacement of cement by 15\% SSP may further mitigate the total shrinkage of UHPC added with $5 \%$ EA. Moreover, the total shrinkage of UHPC decreases with the increasing content of EA. This might be attributed to the synergism effects of the combined use of $\mathrm{CaO}$ and $\mathrm{MgO}$, which could contribute to the expansion and compensate the total shrinkage at both early and later ages, resulting 
a larger ultimate expansion [34]. Previous study suggested that the more stable hydration products from $\mathrm{MgO}$ is expected to perform a long-term expansive effect due to the formation of $\mathrm{Mg}(\mathrm{OH})_{2}$ nano-crystals. These nano-crystals recrystallized into large crystals to press the hardened binder paste and enlarge the microcracks existing in the paste, which thus causes expansion. However, when the EA amount is $8 \mathrm{wt}$ \%, the compressive strength and flowability of UHPC are obviously decreased. Therefore, the suitable combination of SSP and EA can effectively reduce total shrinkage of UHPC without decreasing significantly the workability and mechanical properties.

\subsection{Isothermal Calorimetry}

Figure 5 presents the hydration heat flow of several typical UHPC mixtures by using isothermal calorimetry. As shown in Figure 5a, the maximum heat flow peak of UHPC occurs at about $12 \mathrm{~h}$ and then decreases with the increasing content of SSP incorporated and with the addition of 5\% EA. Consequently, the cumulative heat released from the UHPC pastes containing SSP is lower than that of the control group (Figure 5b). Due to the filler effect, the addition of SSP firstly reduces the cement content and suspends the hydration progress. However, in addition to the filler effects, there is a cement dilution effect, which increases the w/c ratio and provides more available water and space for the cement hydration. This decrease of cumulative heat is due to the decline in the absolute amount of cement involved in the hydration reaction [39]. Additionally, it is clear that the combined of SSP and EA exhibits the lowest hydration peak and total cumulative heat. Moreover, it is evident that that an additional peak is formed around the main hydration heat peak (Figure 5a). This phenomenon is attributed to the formation of mono/hemi-carboaluminate phases [40], which occurs and emits a large amount of heat in the system of UHPC containing LP.
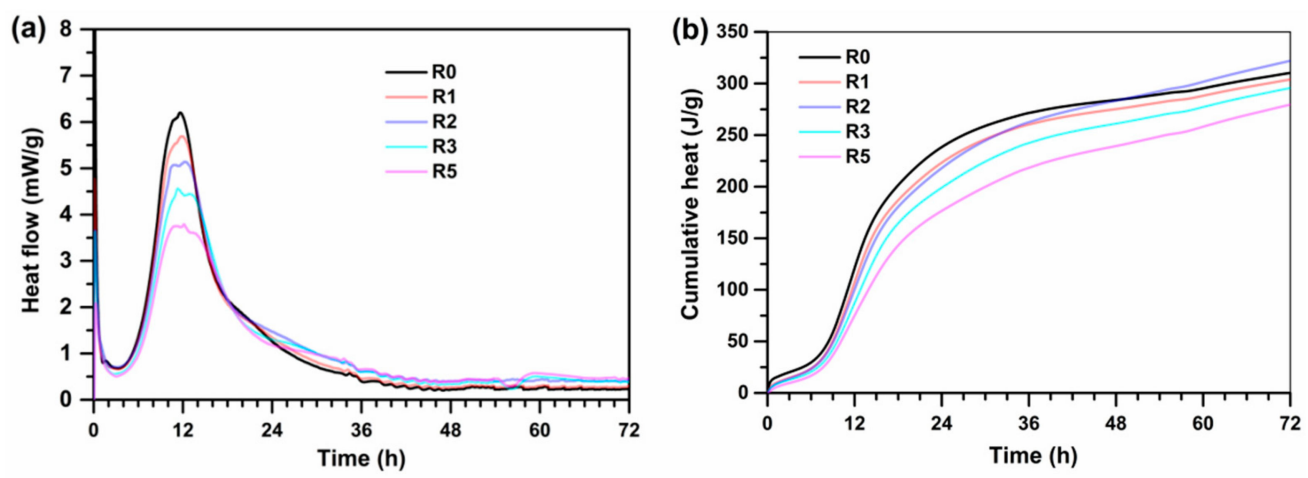

Figure 5. Hydration heat liberation of UHPC powder mixtures (paste): (a) normalized heat flow and (b) normalized total heat.

\subsection{Adiabatic Temperature Rise}

The adiabatic temperature rise test of R0, R2 and R5 samples are presented in Figure 6. From the Figure 6, the adiabatic temperature rise of R0 sample initially increases and then reaches the maximum value. The curves of R2 and R5 samples show a similar tendency. It is also seen that the rate of temperature rise is fast firstly and then reaches a stable value, finally that of the temperature drops slowly until the tested time. During the testing time, the maximum temperature appears at time $1261 \mathrm{~min}$ (about $21 \mathrm{~h}$ ), which means that the hydration heat of the concrete reaches its peak value at $21 \mathrm{~h}$. The maximum adiabatic temperature rises are $65.5^{\circ} \mathrm{C}, 62.9^{\circ} \mathrm{C}$, and $59.5^{\circ} \mathrm{C}$, respectively. These results indicate that the incorporation of SSP and EA in UHPC exhibit positive effects on the adiabatic temperature rise, namely reducing the released hydration heat liberation efficiently. 


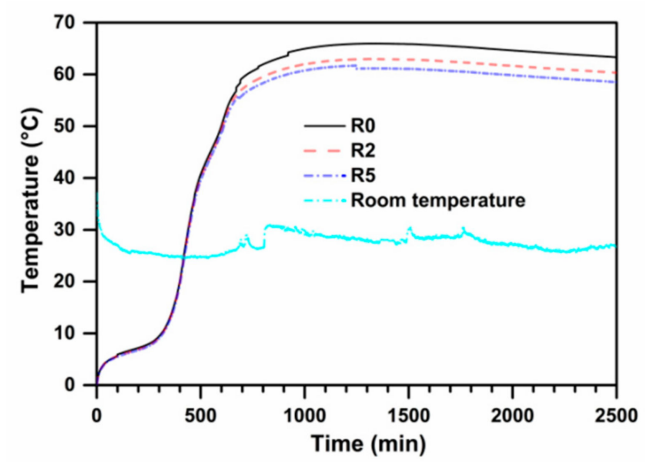

Figure 6. Adiabatic temperature rise curves of UHPC mixtures R0, R2 and R5.

\subsection{A Case Study of Mass UHPC for Bridge Steel Cable Tower}

The steel-concrete section of the cable tower of Peng Gong bridge was divided into two symmetrical zones. The dimension of each section was $6 \times 10 \times 2.5 \mathrm{~m}$. The designed casting volume of UHPC was about $300 \mathrm{~m}^{3}$. The schematic diagram construction on site of mass UHPC section in bridge steel cable tower is shown in Figure 7. The workability and mechanical properties of UHPC by using field sampling are listed in Table 3. During the casting process, the temperature sensors were embedded in the center point, the upper surface midpoint (from surface to $0.625 \mathrm{~m}$ ) and the surface point (from surface to $0.1 \mathrm{~m}$ ), respectively. The measured temperature was demonstrated in Figure 8 . The surface was continuously wet-cured and the side mold is kept insulation and humidification. It is clear that the monitored temperature peak in concrete appeared and reached $90{ }^{\circ} \mathrm{C}$ at $30 \mathrm{~h}$ after casting, the maximum adiabatic temperature rise was $61^{\circ} \mathrm{C}$, while the temperature difference between inside and outside was small during the whole monitoring process, and the maximum value was $15^{\circ} \mathrm{C}$ at $72 \mathrm{~h}$. At seven days, the temperature at center point and surface point both dropped to $56^{\circ} \mathrm{C}$, and the seven-day compressive strength of cored concrete reached $110 \mathrm{MPa}$. The on-site monitored temperature rise in the large volume UHPC of the tower steel-mixed section is consistent with the laboratory adiabatic temperature rise results.

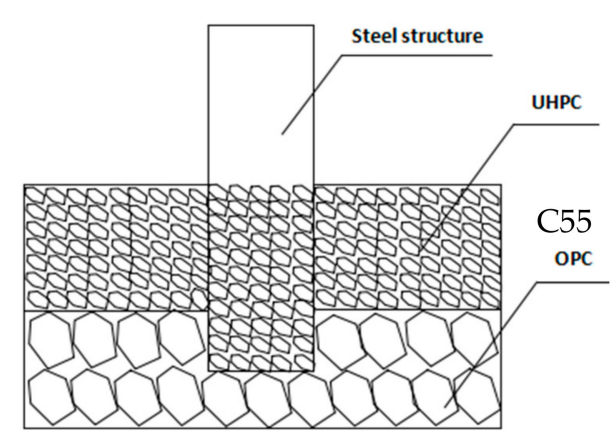

(a)

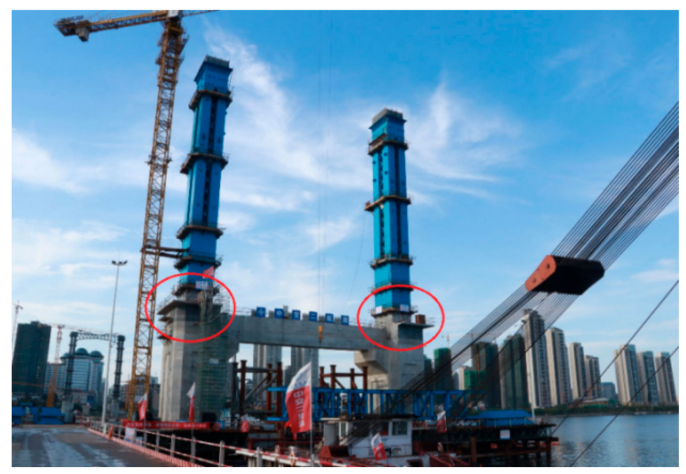

(b)

Figure 7. The schematic diagram (a) and construction on site (b) of mass UHPC for bridge steel cable tower.

Table 3. Performance of UHPC mass concrete used in the cable tower.

\begin{tabular}{cccccccc}
\hline \multicolumn{2}{c}{ Slump Flow $(\mathbf{m m})$} & \multicolumn{3}{c}{ Flexural Strength $(\mathbf{M P a})$} & \multicolumn{3}{c}{ Compressive Strength $(\mathbf{M P a})$} \\
\hline Zero Time & $1 \mathrm{~h}$ & 3 days & 7 days & 28 days & 3 days & 7 days & 28 days \\
610 & 600 & 21.5 & 23.6 & 25.4 & 62.5 & 110.0 & 141.2 \\
\hline
\end{tabular}




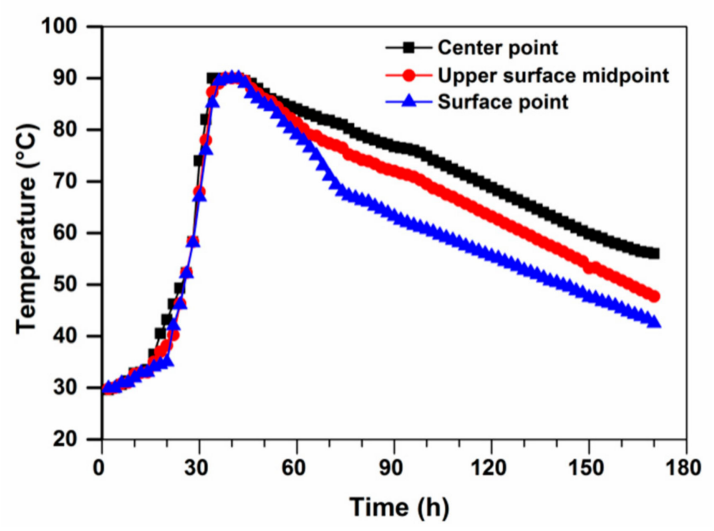

Figure 8. In-situ monitoring of the temperature rise in the mass UHPC.

\section{Conclusions}

This study presents the effect of SSP and EA on the slump flow, compressive strength, drying shrinkage, and hydration heat of mass UHPC used in the steel-concrete section of a cable tower. Based on the obtained experimental results, the following conclusions can be drawn:

1. With the increase of SSP content, the workability and compressive strength of the designed UHPC decreases. This is mainly due to the addition of SSP decreases the stress state between particles, aggregate and mortar, which declines the slump flow and strength. The additional EA has a negative effect on the workability and mechanical properties of UHPC. The suitable contents of SSP and EA are $15 \mathrm{wt} . \%$ and $5 \mathrm{wt} . \%$, respectively.

2. The incorporation of SSP and EA significantly reduces the total shrinkage and hydration release heat of UHPC. The total shrinkage at the age of 180 days is decreased by approximately $40 \%$. Moreover, the adiabatic temperature rise of UHPC containing SSP and EA obtained from the experimental test is $59.5^{\circ} \mathrm{C}$, which is reduced by $6.1^{\circ} \mathrm{C}$ compared with the control group.

3. The monitored temperature peak appears and reaches $90{ }^{\circ} \mathrm{C}$ at $30 \mathrm{~h}$ after casting, while the temperature difference between inside and outside is small during the whole monitoring process, the maximum adiabatic temperature rise is $61^{\circ} \mathrm{C}$ and the maximum temperature difference is $15^{\circ} \mathrm{C}$, respectively. The heat release in the mass UHPC of the tower steel concrete section is consistent with the adiabatic temperature rise gained in laboratory.

Author Contributions: Conceptualization, S.L. and S.C.; methodology, S.L.; software, L.M.; validation, L.M.; formal analysis, S.L.; investigation, S.L., S.C. and M.D.; resources, M.D.; writing-original draft preparation, S.L. and S.C.; writing-review and editing, S.L.; visualization, S.C.; project administration, M.D.; funding acquisition, S.L. All authors have read and agreed to the published version of the manuscript.

Funding: This research was funded by China Communications Construction Group research project (No.2017-ZJKY-PTJS09).

Conflicts of Interest: The authors declare no conflict of interest.

\section{References}

1. Habel, K.; Viviani, M.; Denarié, E.; Brühwiler, E. Development of the mechanical properties of an Ultra-High Performance Fiber Reinforced Concrete (UHPFRC). Cem. Concr. Res. 2006, 36, 1362-1370. [CrossRef]

2. Abbas, S.; Nehdi, M.L.; Saleem, M.A. Ultra-High Performance Concrete: Mechanical Performance, Durability, Sustainability and Implementation Challenges. Int. J. Concr. Struct. Mater. 2016, 10, 271-295. [CrossRef]

3. Tafraoui, A.; Escadeillas, G.; Vidal, T. Durability of the Ultra High Performances Concrete containing metakaolin. Constr. Build. Mater. 2016, 112, 980-987. [CrossRef]

4. Su, Y.; Wu, C.; Li, J.; Li, Z.X.; Li, W. Development of novel ultra-high performance concrete: From material to structure. Constr. Build. Mater. 2017, 135, 517-528. [CrossRef] 
5. Yu, R.; Spiesz, P.; Brouwers, H.J.H. Mix design and properties assessment of Ultra-High Performance Fibre Reinforced Concrete (UHPFRC). Cem. Concr. Res. 2014, 56, 29-39. [CrossRef]

6. Shi, C.; Wu, Z.; Xiao, J.; Wang, D.; Huang, Z.; Fang, Z. A review on ultra high performance concrete: Part I. Raw materials and mixture design. Constr. Build. Mater. 2015, 101, 741-751. [CrossRef]

7. Meng, W.; Khayat, K.H. Mechanical properties of ultra-high-performance concrete enhanced with graphite nanoplatelets and carbon nanofibers. Compos. Part B Eng. 2016, 107, 113-122. [CrossRef]

8. Meng, W.; Khayat, K.H.; Bao, Y. Flexural behaviors of fiber-reinforced polymer fabric reinforced ultra-high-performance concrete panels. Cem. Concr. Compos. 2018, 93, 43-53. [CrossRef]

9. Azmee, N.M.; Shafiq, N. Ultra-high performance concrete: From fundamental to applications. Case Stud. Constr. Mater. 2018, 9, e00197. [CrossRef]

10. Zhou, M.; Lu, W.; Song, J.; Lee, G.C. Application of Ultra-High Performance Concrete in bridge engineering. Constr. Build. Mater. 2018, 186, 1256-1267. [CrossRef]

11. Hussein, H.H.; Sargand, S.M.; Al Rikabi, F.T.; Steinberg, E.P. Experimental validation of optimized ultra-high-performance concrete shear key shape for precast pre-stressed adjacent box girder bridges. Constr. Build. Mater. 2018, 190, 178-190. [CrossRef]

12. Meng, W.; Yao, Y.; Mobasher, B.; Khayat, K.H. Effects of loading rate and notch-to-depth ratio of notched beams on flexural performance of ultra-high-performance concrete. Cem. Concr. Compos. 2017, 83, 349-359. [CrossRef]

13. Zhang, Y.; Zhu, Y.; Yeseta, M.; Meng, D.; Shao, X.; Dang, Q.; Chen, G. Flexural behaviors and capacity prediction on damaged reinforcement concrete $(\mathrm{RC})$ bridge deck strengthened by ultra-high performance concrete (UHPC) layer. Constr. Build. Mater. 2019, 215, 347-359. [CrossRef]

14. Wang, W.; Wu, C.; Liu, Z. Compressive behavior of hybrid double-skin tubular columns with ultra-high performance fiber-reinforced concrete (UHPFRC). Eng. Struct. 2019, 180, 419-441. [CrossRef]

15. Korpa, A.; Kowald, T.; Trettin, R. Phase development in normal and ultra high performance cementitious systems by quantitative X-ray analysis and thermoanalytical methods. Cem. Concr. Res. 2009, 39, 69-76. [CrossRef]

16. Shaikh, F.U.A.; Luhar, S.; Arel, H.Ş.; Luhar, I. Performance evaluation of Ultrahigh performance fibre reinforced concrete-A review. Constr. Build. Mater. 2020, 232, 117152. [CrossRef]

17. Meng, W.; Kumar, A.; Khayat, K.H. Effect of silica fume and slump-retaining polycarboxylate-based dispersant on the development of properties of portland cement paste. Cem. Concr. Compos. 2019, 99, 181-190. [CrossRef]

18. Wang, D.; Shi, C.; Wu, Z.; Xiao, J.; Huang, Z.; Fang, Z. A review on ultra high performance concrete: Part II. Hydration, microstructure and properties. Constr. Build. Mater. 2015, 96, 368-377. [CrossRef]

19. Kodur, V.K.R.; Bhatt, P.P.; Soroushian, P.; Arablouei, A. Temperature and stress development in ultra-high performance concrete during curing. Constr. Build. Mater. 2016, 122, 63-71. [CrossRef]

20. Liu, K.; Yu, R.; Shui, Z.; Li, X.; Guo, C.; Yu, B.; Wu, S. Optimization of autogenous shrinkage and microstructure for Ultra-High Performance Concrete (UHPC) based on appropriate application of porous pumice. Constr. Build. Mater. 2019, 214, 369-381. [CrossRef]

21. Ganesh, P.; Murthy, A.R. Tensile behaviour and durability aspects of sustainable ultra-high performance concrete incorporated with GGBS as cementitious material. Constr. Build. Mater. 2019, 197, 667-680. [CrossRef]

22. Yazıc1, H.; Yiğiter, H.; Karabulut, A.Ş.; Baradan, B. Utilization of fly ash and ground granulated blast furnace slag as an alternative silica source in reactive powder concrete. Fuel 2008, 87, 2401-2407. [CrossRef]

23. Hüsken, G.; Brouwers, H.J.H. A new mix design concept for earth-moist concrete: A theoretical and experimental study. Cem. Concr. Res. 2008, 38, 1246-1259. [CrossRef]

24. Bahedh, M.A.; Jaafar, M.S. Ultra high-performance concrete utilizing fly ash as cement replacement under autoclaving technique. Case Stud. Constr. Mater. 2018, 9, e00202. [CrossRef]

25. Lin, Y.; Yan, J.; Wang, Z.; Fan, F.; Zou, C. Effect of silica fumes on fluidity of UHPC: Experiments, influence mechanism and evaluation methods. Constr. Build. Mater. 2019, 210, 451-460. [CrossRef]

26. Van Tuan, N.; Ye, G.; Van Breugel, K.; Fraaij, A.L.; Dai Bui, D. The study of using rice husk ash to produce ultra high performance concrete. Constr. Build. Mater. 2011, 25, 2030-2035. [CrossRef]

27. Ghafari, E.; Costa, H.; Júlio, E. Critical review on eco-efficient ultra high performance concrete enhanced with nano-materials. Constr. Build. Mater. 2015, 101, 201-208. [CrossRef] 
28. Yu, R.; Spiesz, P.; Brouwers, H.J.H. Development of an eco-friendly Ultra-High Performance Concrete (UHPC) with efficient cement and mineral admixtures uses. Cem. Concr. Compos. 2015, 55, 383-394. [CrossRef]

29. Lothenbach, B.; Le Saout, G.; Gallucci, E.; Scrivener, K. Influence of limestone on the hydration of Portland cements. Cem. Concr. Res. 2008, 38, 848-860. [CrossRef]

30. Zunino, F.; Lopez, M. Decoupling the physical and chemical effects of supplementary cementitious materials on strength and permeability: A multi-level approach. Cem. Concr. Compos. 2016, 65, 19-28. [CrossRef]

31. Liu, J.; Wang, D. Influence of steel slag-silica fume composite mineral admixture on the properties of concrete. Powder Technol. 2017, 320, 230-238. [CrossRef]

32. Xie, T.; Fang, C.; Ali, M.M.; Visintin, P. Characterizations of autogenous and drying shrinkage of ultra-high performance concrete (UHPC): An experimental study. Cem. Concr. Compos. 2018, 91, 156-173. [CrossRef]

33. Sun, Y.; Yu, R.; Shui, Z.; Wang, X.; Qian, D.; Rao, B.; Huang, J.; He, Y. Understanding the porous aggregates carrier effect on reducing autogenous shrinkage of Ultra-High Performance Concrete (UHPC) based on response surface method. Constr. Build. Mater. 2019, 222, 130-141. [CrossRef]

34. Shen, P.; Lu, L.; He, Y.; Wang, F.; Lu, J.; Zheng, H.; Hu, S. Investigation on expansion effect of the expansive agents in ultra-high performance concrete. Cem. Concr. Compos. 2020, 105, 103425. [CrossRef]

35. Wang, X.; Yu, R.; Song, Q.; Shui, Z.; Liu, Z.; Wu, S.; Hou, D. Optimized design of ultra-high performance concrete (UHPC) with a high wet packing density. Cem. Concr. Res. 2019, 126, 105921. [CrossRef]

36. Liu, K.; Yu, R.; Shui, Z.; Li, X.; Ling, X.; He, W.; Yi, S.; Wu, S. Effects of Pumice-Based Porous Material on Hydration Characteristics and Persistent Shrinkage of Ultra-High Performance Concrete (UHPC). Materials 2018, 12, 11. [CrossRef]

37. Song, Q.; Yu, R.; Shui, Z.; Wang, X.; Rao, S.; Lin, Z.; Wang, Z. Key parameters in optimizing fibres orientation and distribution for Ultra-High Performance Fibre Reinforced Concrete (UHPFRC). Constr. Build. Mater. 2018, 188, 17-27. [CrossRef]

38. Meng, W.; Khayat, K.H. Effect of graphite nanoplatelets and carbon nanofibers on rheology, hydration, shrinkage, mechanical properties, and microstructure of UHPC. Cem. Concr. Res. 2018, 105, 64-71. [CrossRef]

39. Meng, W.; Khayat, K. Effects of saturated lightweight sand content on key characteristics of ultra-high-performance concrete. Cem. Concr. Res. 2017, 101, 46-54. [CrossRef]

40. Adu-Amankwah, S.; Zajac, M.; Stabler, C.; Lothenbach, B.; Black, L. Influence of limestone on the hydration of ternary slag cements. Cem. Concr. Res. 2017, 100, 96-109. [CrossRef] 